\title{
Kinetics and mechanism of thermal degradation of vegetable-tanned leather fiber
}

\author{
Jie Liu, Lan Luo, Yadi Hu, Fang Wang, Xuejing Zheng and Keyong Tang* (D)
}

\begin{abstract}
Thermal degradation of vegetable-tanned leather fiber (VLF) was investigated by thermogravimetric analysis aiming to know the exact kinetics and degradation mechanism. The thermogravimetric (TG) and differential thermogravimetric (DTG) curves showed that decomposition of the VLF occurs mainly in the range of $150-600^{\circ} \mathrm{C}$, and the latter exhibits asymmetrical peak with a pronounced shoulder. The decomposition process was first analyzed by deconvolution of the experimental DTG curves, followed by reconstruction of the weight loss profiles of two individual processes. Several common isoconversional approaches were applied to calculate the activation energy over a wide range of conversion for the sample, including modified Kissinger-Akahira-Sunose (MKAS), Friedman, and Flynn-Wall-Ozawa. The average activation energy of vegetable-tanned leather fiber was found to be $241.9 \mathrm{~kJ} \mathrm{~mol}^{-1}$ by MKAS method. The activation energy values obtained for the pseudocomponents representing highly-crosslinked and low-crosslinked collagen in VLF were given as 190.6 and $124.8 \mathrm{k} \mathrm{mol}^{-1}$, respectively. Generalized master plots results suggested that the reaction mechanism for highly-crosslinked collagen follows the random nucleation and growth process at conversion values lower than 0.5. When the conversion is higher than 0.5 , the mechanism tends to random scission model. For low-crosslinked collagen, the degradation is mainly governed by random nucleation and nuclei growth. The gaseous products of VLF thermal degradation were analyzed with an online-coupled TG-Fourier transform infrared spectroscopy system.
\end{abstract}

Keywords: Leather, Collagen, Thermal degradation kinetics, Activation energy, Master plots method

\section{Introduction}

Leather tanning processes generate huge amounts of wastes, which gives rise to serious concerns on environmental problem as well as on gradually increased treatment costs. It has been reported that only about $15-20 \%$ (percent by weight) of wet-salted raw hide is transformed into durable leather. Most of the rest of the collagenous materials are disposed as solid wastes, including tanned shavings, trimmings, splits, buffing dusts, strips, and scraps [1, 2]. It was estimated that about 19.67 billion sq. $\mathrm{ft}$. of commercial leather is produced every year from a global scale [3], while about 130 million pieces of bovine leather were produced each year in China. During this process, about 250,000 tons of tanned leather wastes were generated [4]. It was been estimated that million tons of

\footnotetext{
* Correspondence: keyongtangzzu@yahoo.com

School of Materials Science and Engineering, Zhengzhou University, Zhengzhou 450001, Henan, China
}

\section{Springer Open}

(c) The Author(s). 2019 Open Access This article is distributed under the terms of the Creative Commons Attribution 4.0 International License (http://creativecommons.org/licenses/by/4.0/), which permits unrestricted use, distribution, and reproduction in any medium, provided you give appropriate credit to the original author(s) and the source, provide a link to the Creative Commons license, and indicate if changes were made. the world [5]. The disposal of these wastes contributes substantial quantities of toxic metals, inorganics and organics to the environment. Consequently, research activities for the reuse of tannery solid wastes were initiated and then accelerated in recent years because of the increasing pressure from environmental protection voices. To date, an enormous amount of research has been devoted to converting tannery wastes into valuable products, such as animal feeds, fertilizers, surfactants, leather chemicals, adsorbents, water treatment materials, energy sources and adhesives, etc. [6-8].

Recently, many efforts have been made to produce polymer composites from tannery wastes for various applications, including packaging, building, footwear, clothing, and so on [9]. Such potential applications would be greatly benefited from the hierarchical structure and proteinaceous nature of leather fiber. Teklay, Liu, and Xia et al.

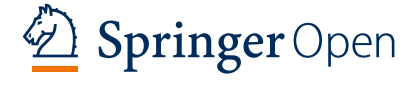


studied the production of composites from leather wastes through a solution mixing technique [10-12]. They utilized water-soluble or water-dispersible polymers as the matrix to bind leather fibers. Besides, some studies have been conducted to fabricate leather fiber-filled composites with thermoplastic matrix through modern polymer processing methods, such as calendering, extrusion, and injection molding, etc. [13-16]. Unlike solution mixing technique, these polymer processing operations are usually performed at high temperatures to obtain viscous polymer melts. El-Sabbagh et al. fabricated leather waste/ acrylonitrile butadiene rubber composites in an electrically heated auto-controlled hydraulic pressure at $162{ }^{\circ} \mathrm{C}$ [13]. Ramaraj investigated the production of acrylonitrilebutadiene-styrene/leather fiber composites by extrusion with temperature profile of $175-215^{\circ} \mathrm{C}$ [14]. Mohamed et al. prepared nylon 6/leather wastes composites in a Brabender apparatus at $230{ }^{\circ} \mathrm{C}$ [15]. Ambrósio et al. blended leather fibers with poly (vinylbutyral) at the temperature profile of $155-175^{\circ} \mathrm{C}$ and $180^{\circ} \mathrm{C}$ in the extrusion barrel and head, respectively [16].

The major component of tannery solid waste is collagen, which tends to denature and then degrade at high temperatures. Therefore, the thermal stability of leather fiber is a very important parameter in the production of leather fiber-reinforced and/or filled composites. The thermal degradation of leather fiber may provide undesirable properties to the composites. In order to develop polymer composites system based on leather fibers with good properties, it is essential to acquire deep knowledge about the thermal degradation behaviors and kinetics of leather fibers. However, the thermal degradation behaviors, kinetics and mechanisms of leather fibers have not been extensively studied. To some extent, it may be due to the complexity of leather samples and the fact that there are many factors involved in the thermal degradation. Roduit and co-workers discussed the thermal stability and kinetics of parchment by using thermal analysis-mass spectrometry technique [17]. Caballero et al. studied the thermal decomposition kinetics of chrome-tanned leather by employing thermogravimetric/differential thermogravimetric (TG/DTG) analysis in different atmospheres [18]. In addition, pyrolysis of leather wastes has been studied in order to get useful materials. This process was carried out in an inert gas (nitrogen or helium) by heating the samples at high temperatures. Yilmaz et al. reported a pyrolysis approach $\left(450\right.$ and $\left.600^{\circ} \mathrm{C}\right)$ for the preparation of useful absorbent materials from shavings and buffing dust [19]. Using waste crust as precursors, hierarchical porous carbons were obtained by pre-carbonization and $\mathrm{KOH}$ chemical activation of the waste at high temperatures (up to $900^{\circ} \mathrm{C}$ ) [20]. In addition to the traditional heating, microwave heating method has been utilized to prepare activated carbon materials from leather waste [21].
In the present paper, thermal degradation behavior of vegetable-tanned leather fiber was studied using thermogravimetric analysis (TGA). TGA is very useful in determining the reaction kinetics as well as the mechanisms of thermal degradation processes. The objectives of this work were to obtain the kinetic parameters and mechanism of thermal degradation using isoconversional and generalized master plots methods, respectively. Considering the complexity, the kinetic analysis was first performed by deconvolution of the experimental DTG curves, followed by reconstruction of the TG profiles of individual processes. Up to now, very few study has been reported on thermal degradation kinetics of leather samples by using the deconvolution and generalized master plot methods.

\section{Theoretical background}

\subsection{Kinetic methods}

In dynamic studies, kinetic parameters can be obtained by different approaches. Generally, the apparent solidstate reaction rate is expressed as [22]:

$$
\frac{d \alpha}{d t}=k(\mathrm{~T}) f(\alpha)=A f(\alpha) e^{-\frac{E}{R T}}
$$

where $\alpha$ is conversion; $k(T)$ is the rate constant; $f(\alpha)$ is the mechanism model; $T$ is the absolute temperature, $\mathrm{K}$; $E$ is the apparent activation energy, $\mathrm{kJ} \mathrm{mol}^{-1} ; A$ is the pre-exponential factor of Arrhenius, $\mathrm{s}^{-1}$; and $R$ is the universal gas constant, $8.314 \mathrm{~J} \mathrm{~mol}^{-1} \mathrm{~K}^{-1}$.

In a linear non-isothermal TGA experiment, by introducing the heating rate $\beta(\beta=\mathrm{d} T / \mathrm{d} t)$, the kinetic reaction rate of a single-step kinetic process becomes [22]:

$$
\frac{d \alpha}{d T}=\left(\frac{A}{\beta}\right) e^{-\frac{E}{R T}} f(\alpha)
$$

If a process involves two parallel sub-reactions, the overall transformation process is expressed as:

$$
\frac{d \alpha}{d t}=k_{1}\left(T_{1}\right) f_{1}\left(\alpha_{1}\right)+k_{2}\left(T_{2}\right) f_{2}\left(\alpha_{2}\right)
$$

where $\alpha_{1}$ and $\alpha_{2}$ are the two specific conversions, associated with the two individual sub-reactions or steps [22].

\subsection{Iso-conversional method}

In the kinetic study on the thermal degradation, it is commonly known that iso-conversional methods are very useful research tools for calculating apparent activation energy [22]. The following frequently-used isoconversional methods were applied in this work [23]:

Modified Kissinger-Akahira-Sunose (MKAS) method. 


$$
\operatorname{In}\left(\frac{\beta_{i}}{T_{\alpha, i}^{1.92}}\right)=\text { Const }-1.0008\left(\frac{E_{\alpha}}{R T_{\alpha}}\right)
$$

Flynn-Wall-Ozawa (FWO) method.

$$
\text { In } \beta_{i}=\text { Const }-1.052\left(\frac{E_{\alpha}}{R T_{\alpha}}\right)
$$

Friedman (FR) method.

$$
\operatorname{In}\left(\frac{d \alpha}{d t}\right)_{\alpha}=\operatorname{In}\left[f(\alpha) A_{\alpha}\right]-\frac{E_{\alpha}}{R T_{\alpha}}
$$

In Eqs. (4)-(6), the subscript $\alpha$ refers to the corresponding parameters or data points at certain conversion.

\subsection{Generalized master plots method}

By introducing a parameter of generalized time $(\theta)$, the generalized master plots method can be established to estimate the kinetic mechanism of the thermal degradation process [24]. According to the definition, the generalized time is expressed as:

$$
\theta=\int_{0}^{t} e^{(-E / R T)} d t
$$

Differentiating Eq. (7) with respect to $t$, followed by combining with Eq. (1), the reduced generalized reaction rate can be expressed as:

$$
\frac{d \alpha}{d \theta}=A f(\alpha)
$$

The $d \alpha / d \theta$ denotes the reaction rate extrapolated at infinite $\mathrm{T}$. Using $\alpha=0.5$ as reference point leads to the form of:

$$
\frac{d \alpha / d \theta}{(d \alpha / d \theta)_{0.5}}=\frac{f(\alpha)}{f(0.5)}
$$

Eq. (9) shows that the expression on the left-hand side of the equation would be identical to $f(\alpha) / f(0.5)$ for a given $\alpha$ when the proper $f(\alpha)$ is considered [25]. In addition, the following equation can be derived from Eqs. (1) and (7):

$$
\frac{d \alpha}{d \theta}=\frac{d \alpha}{d t} e^{E / R T}
$$

As a result, the following equation can be obtained:

$$
\frac{d \alpha / d \theta}{(d \alpha / d \theta)_{0.5}}=\frac{d \alpha / d t}{(d \alpha / d t)_{0.5}} \frac{e^{(E / R T)}}{e^{\left(E / R T_{0.5}\right)}}
$$

where $T_{0.5}$ is the temperature when $\alpha=0.5$. For a singlestep process, the most probable kinetic mechanism (or model) can be estimated by comparing the experimental and theoretical master plots [22]. The commonly used kinetic models and functions for solid-state reactions are shown in Additional file 1: Table S1 [22, 25, 26].

\section{Experimental}

\subsection{Materials}

The vegetable-tanned leather fiber (VLF) used in this study was obtained by grinding method. The raw sample was a dried bovine splitting from a vegetable tannery (Wickett \& Craig, PA, USA), which has been tanned with vegetable tannins. Untanned hide powder was prepared from bovine hides de-haired and limed as described in an earlier report [27]. The leather/hide samples were washed three times with distilled water and vacuum-dried for $24 \mathrm{~h}$ at $30^{\circ} \mathrm{C}$. Dried hide and leather pieces were cut into approximately 2.5 to $5.5 \mathrm{~cm}^{2}$ pieces and then grounded in a Wiley Mill using 2-mm screen. After the pieces were ground up, the fibers were collected and stored in sealed plastic bags before analysis. The digital photo and SEM image of the obtained fibers are shown in Additional file 1: Figure S1.

\subsection{Thermogravimetric analysis}

Thermogravimetric tests of the hide/leather fiber samples were carried out in a Q500 thermogravimetric analyzer (TA Instruments, USA). The purge $\mathrm{N}_{2}$ flow rates were 40 and $60 \mathrm{~mL} \mathrm{~min}^{-1}$ in the balance and sample, respectively. Approximately $6-8 \mathrm{mg}$ of fiber sample was weighed and placed in the platinum crucible. The temperature increased from room temperature up to $800^{\circ} \mathrm{C}$ at five different heating rates $\left(2,5,10,20\right.$ and $\left.40^{\circ} \mathrm{C} \mathrm{min}^{-1}\right)$.

The TG-Fourier transform infrared spectroscopy (TGFTIR) experiments were conducted on a coupling device of model STA 449F3 Jupiter TGA analyzer (Netzsch, Germany) and FTIR spectrophotometer TENSOR-II model (Bruker, Germany). The experimental conditions were as follows: $10 \mathrm{mg}$ sample; temperature range from 40 to $900^{\circ} \mathrm{C}$; heating rate $10^{\circ} \mathrm{C} \mathrm{min}^{-1} ; \mathrm{N}_{2}$ flow rate $60 \mathrm{~mL} \mathrm{~min}^{-1}$.

\section{Results and discussion}

\subsection{The overall TG/DTG curves}

The overall TG/DTG curves for VLF at different heating rates are presented in Fig. 1. Three regions appeared in the temperature range from room temperature to $800^{\circ} \mathrm{C}$, corresponding to water-removal, main decomposition (active pyrolysis) and passive pyrolysis, respectively. The observed mass loss (region 1) from room temperature to $150^{\circ} \mathrm{C}$ can be attributed to the evaporation of absorbed and bound water in the VLF. The main step of mass loss from 150 to $600^{\circ} \mathrm{C}$ (region 2) is assigned to the decomposition of the collagen. It was reported that the gas released from leather sample by pyrolysis under $\mathrm{N}_{2}$ atmosphere included $\mathrm{H}_{2}, \mathrm{CH}_{4}, \mathrm{CO}, \mathrm{CO}_{2}, \mathrm{C}_{2} \mathrm{H}_{4}, \mathrm{C}_{2} \mathrm{H}_{6}$, $\mathrm{SO}_{2}, \mathrm{NH}_{3}$, toluene and other hydrocarbons [28-30]. The TG curve in Fig. 1(a) and showed that the main decomposition, also referred to as active pyrolysis, begins at 

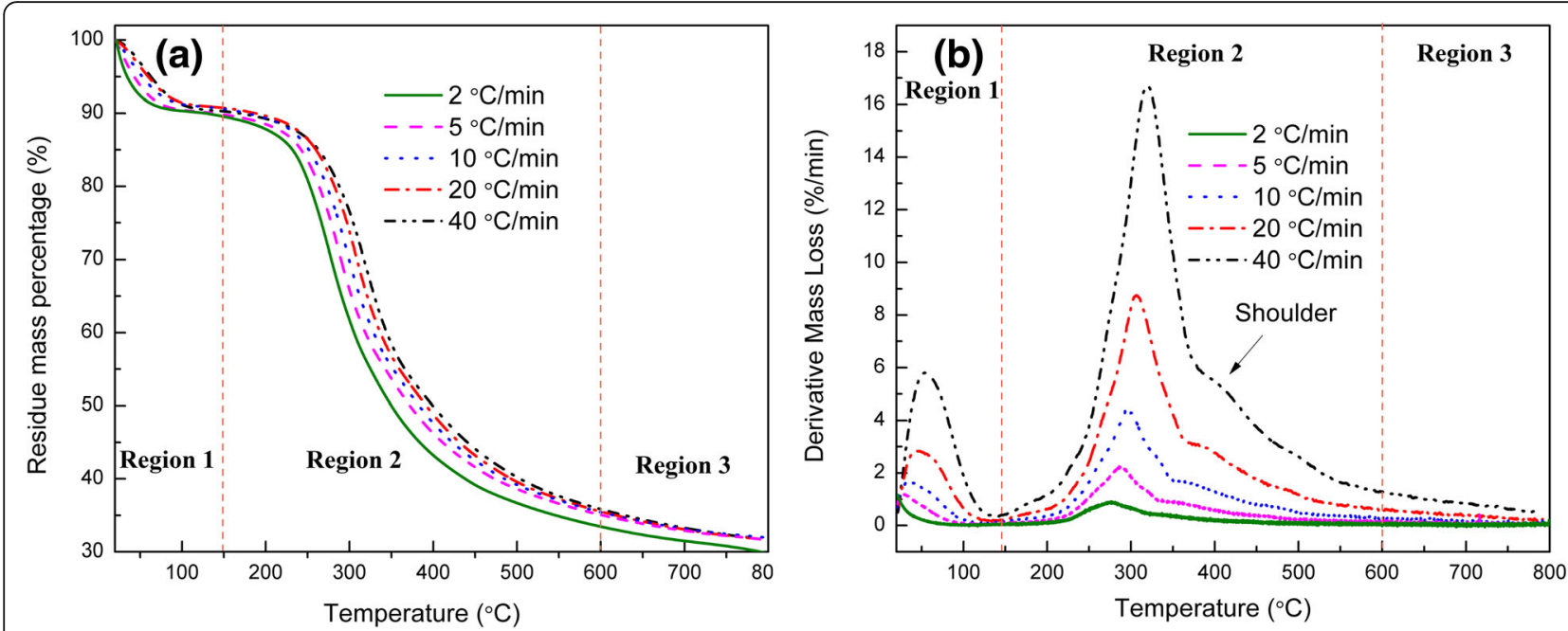

Fig. 1 (a) TG and (b) DTG curves of vegetable-tanned leather fiber

about $150-200^{\circ} \mathrm{C}$ regardless of the heating rate, followed by a rapid mass loss process from 200 to $600^{\circ} \mathrm{C}$. It is known that DTG curve is effective in distinguishing subtle changes in the slope of the TG curve. As can be observed in Fig. 1(b), the differential mass loss versus temperature profile exhibited an asymmetric curve in the second region, which has a sharp main peak accompanied by a high-temperature shoulder at about $400{ }^{\circ} \mathrm{C}$. The shoulder peak provided significant hints on the complexity of the thermal decomposition of the leather fiber. Bañon et al. similarly reported the emergence of shoulder peak in the DTG curve of chrome tanned leather [30]. Marcilla et al. evaluated the effect of tanning process on pyrolysis of tannery wastes and a shoulder peak could be clearly seen on the DTG curves of leathers tanned with different tanning agents [28]. Gil et al. also observed a distinct peak at temperature range $430-480^{\circ} \mathrm{C}$ [29], while Caballero et al. did not find any more peaks except for the dehydration and main decomposition peaks [18]. This disparity may be due to the differences in leather samples and experimental conditions used by the researchers. With further increase in temperature, a long tail was observed at high temperature range $\left(600-800^{\circ} \mathrm{C}\right)$ and manifest extremely low mass loss rate, which can be ascribed to the continuous pyrolysis of very stable residues. This region (region 3 ) is referred as passive pyrolysis region because the mass loss rate is very much lower compared to that in region 2 .

\subsection{Kinetic analysis}

\subsubsection{Isoconversional method}

Because the second region (region 2) is the main stage in degradation process of VLF, only the mass loss between 150 and $600{ }^{\circ} \mathrm{C}$ was discussed in the following kinetic analysis. The main advantage of model-free isoconversional methods is that the kinetic parameters can be calculated before the establishment of exact reaction model. Further more, it has been concluded that isoconversional methods can be applied to both the single-step and multi-step processes [22]. In the present work, the TG results were elaborated according to MKAS, FWO and FR methods to calculate the $E$ as a function of $\alpha$. Before calculation, the experimental conversions $(\alpha)$ in region 2 were normalized to vary from 0 to 1 in order to emphasize the thermal decomposition process by eliminating the influence of water evaporation. According to Eqs. (4), (5) and (6), firstly, $\ln \left(\beta / T^{1.92}\right), \ln (\beta)$, and $\ln (\mathrm{d} \alpha / \mathrm{d} t)$ were linearly plotted against the reciprocal of temperature $(1 / T)$. Then, the activation energy values can be obtained from the slopes of the fitted lines at various characteristic conversions and the results are shown in Fig. 2(a). In order to reveal the dependency of $E_{\alpha}$ vs. $\alpha$. in view of the fact that the $E_{\alpha}$ dependence plays an important role in uncovering the multi-step kinetics and mechanisms, The $\alpha$ range of 0.05 to 0.9 with a step size of 0.05 was used in the present work [22]. It was found that the resulting correlation coefficients $R^{2}$ of the linear regressions are in the range between 0.972 and 0.998 , suggesting that the obtained $E_{\alpha}$ values are accurate and reliable.

It can be observed from Fig. 2(a) that the $E$ values estimated by MKAS, FWO and FR methods show distinct dependence on the conversion, indicating that the VLF thermal degradation is unlikely to be dominated by a single-step mechanism [22]. The average value of activation energy $\left(E_{0}\right)$ calculated by MKAS approach is $241.9 \mathrm{~kJ}$ $\mathrm{mol}^{-1}$, which is basically near to the results obtained by FWO $\left(252.2 \mathrm{~kJ} \mathrm{~mol}^{-1}\right)$ and FR $\left(252.6 \mathrm{~kJ} \mathrm{~mol}^{-1}\right)$ methods. However, downtrends can be observed in the conversion range of $0.05-0.3$ and $0.6-0.7$. As mentioned by Vyazovkin et al., if the deviation between the maximum and minimum values of activation energy is smaller than 20 

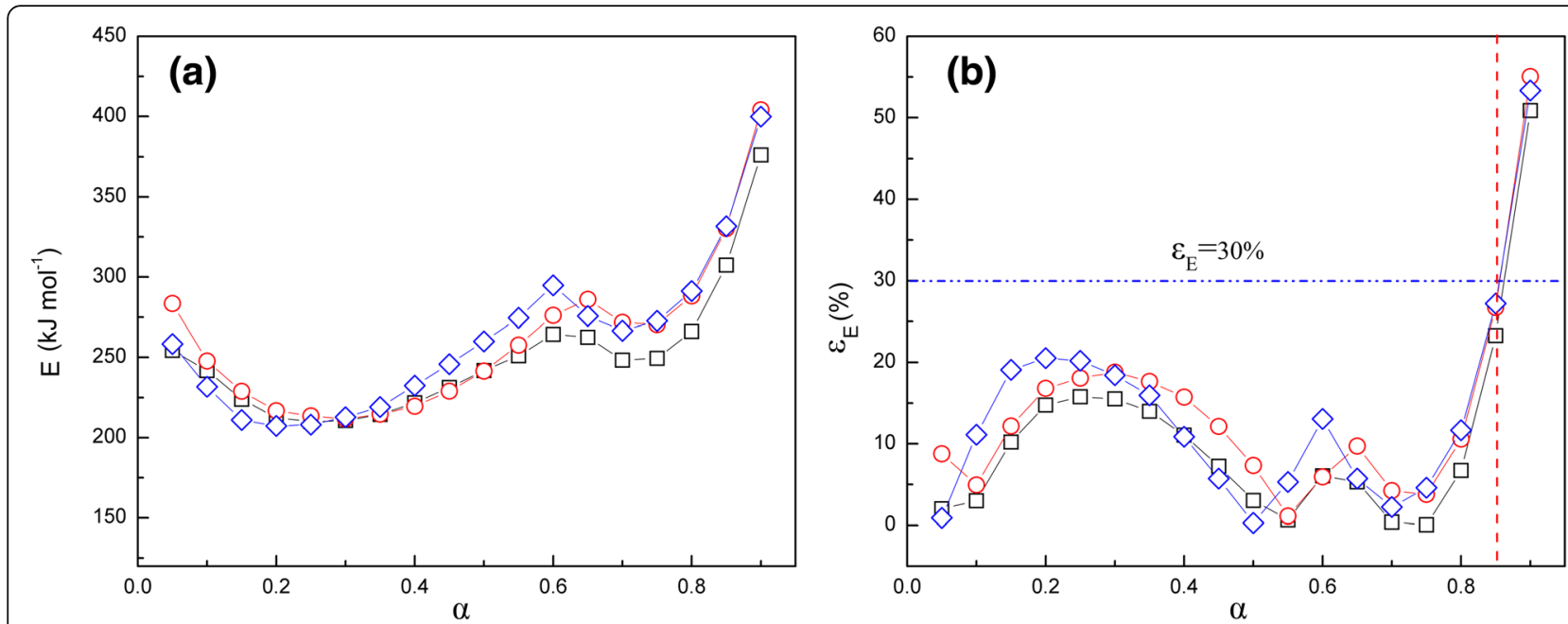

Fig. 2 (a) Activation energy calculated by FWO, MKAS, and FR methods; (b) absolute deviation $\left(\varepsilon_{\mathrm{E}}\right)$ vs. a

$30 \%$ to their average value, the thermal decomposition process can be considered to be a single reaction mechanism. Otherwise, the process should be supposed to be multi-step mechanism [22]. Figure 2(b) presents the relationship between the absolute deviation $\left(\varepsilon_{E}=\left|E_{\alpha}-E_{O}\right| \times\right.$ $\left.100 / E_{0}, \%\right)$ of $E_{\alpha}$ vs. $E_{O}$ and $\alpha$. As can be seen, the $\varepsilon_{E}$ values are remarkably higher than $30 \%$ at $\alpha>0.85$. This deviation may be due to the secondary reaction between gaseous products and pyrolyzed char. This reaction was also believed to be responsible for the long tail of the DTG curves at high temperature and had been frequently found in heterogeneous reaction systems [26-28]. Additionally, another influencing factor affecting the variation of $E$ beyond the range of $0.1<\alpha<0.9$ could be the minor inaccuracies in the baseline determination [22].

\subsubsection{Deconvolution method}

For a complicated pyrolysis process, it is supposed that several apparent sub-reactions and mechanisms may be involved depending on the temperature [31]. As a consequence, the shape and slope of the TG curves at different stages will change. Accordingly, the DTG profiles may have asymmetrical peaks with more or less pronounced shoulders, or even separated multiple peaks [32]. In this case, the $E$ value estimated by isoconversional method actually reflects the contributions of several subreactions to the overall reaction rate. In the present study, even though the absolute deviation generated by $E_{\alpha}$ variation to $E_{O}$ is smaller than $30 \%$ in most of the conversions (see Fig. 2(b)), the pronounced shoulder peak observed at high temperatures can not be ignored. In a broad sense, $E$ represents the energy barrier for certain reaction to break through. A comparison of the average value of $E_{\alpha}$ estimated by MKAS method in the conversion range of $0.05-0.60$ and $0.60-0.85$ indicated that it increases significantly from
236.7 to $289.3 \mathrm{~kJ} \mathrm{~mol}^{-1}$. This suggests that there might be a multi-step reaction during the thermal decomposition of VLF. The single-step model is not suitable for describing the kinetics of the complex decomposition process in a wide range of conversions.

To better understand the mechanisms of thermal degradation of materials with such mass loss patterns, Vyazovkin et al. suggested the use of deconvolution method and analyzed their kinetics individually [22]. Deconvolution provides a way to describe qualitatively and quantitatively the progress of complex reaction. Many researchers performed deconvolution method to study the kinetics of thermal decomposition by thermogravimetry. In the beginning, deconvolution method was applied to the asymmetric experimental DTG curves. Later on, a series of TG curves which represent the individual single-step processes were reconstructed from the deconvoluted DTG data [32-35]. In this way, Katsikas et al. proposed an improvement of Flynn-Wall method of determining $E$ values to address the complexity of thermal degradation behavior of polymers [32]. After the deconvolution and reconstruction steps, they applied Flynn-Wall method separately to the individual sets of reconstructed TG curves. Moreover, deconvolution method has also been previously used to illustrate the contributions of different components to the global thermal degradation rate. For example, Aboyade et al. [33] studied the thermal degradation kinetics of lignocellulosic pseudocomponents through the deconvolutionreconstruction approach. Shanmugharaj et al. [34] and Roeder et al. [35] investigated the thermal decomposition behaviors of different polymers by various deconvolution methods.

All the DTG curves in Fig. 1(b) in the temperature range 150-600 ${ }^{\circ} \mathrm{C}$ were subjected to deconvolution analysis, with the help of a free scientific data analysis software named 
SciDAVis [36]. For materials with overlapped multireactions, it is always a challenge to reasonably locate the peaks related to certain sub-reactions. The experimental DTG curves were fitted with several types of functions, including Gaussian and Lorentzian, and it was found that Lorentzian method provides better fit to both peaks after baselines were deducted. The adjusted $R^{2}$ values, which are used for the characterization of the goodness of fit, are 0.997 and 0.995 for Lorentzian and Gaussian regression models, respectively. An example of Lorentzian fit is illustrated in Fig. 3 (heating rate: $20^{\circ} \mathrm{C} \mathrm{min}^{-1}$ ), the magnitude of the area of the deconvoluted DTG curves is directly proportional to the amount of VLF degraded by each mechanism. From the figure it can be seen that the two degradation processes appeared in the temperature range $150-600{ }^{\circ} \mathrm{C}$ are well fitted by Lorentzian function. In the study of thermal denaturation behaviors of collagen at lower temperatures, the multiple nature of collagen has been confirmed by DSC for hide and skin. It was concluded that the distinct sheath-core thermal stability, which is related to unraveling of triple helical structure of collagen, was attributed to uneven fibril crosslinking [37, 38]. Therefore, the two peaks found here can also be assigned to different collagen amount in the fibers. The details of the decomposition kinetics were uncovered by the deconvolution of experimental DTG peak, followed by the calculation of kinetic parameters from reconstructed TG curves of the two collagen groups distinguished by their thermal resistance. Thus, the DTG profile of VLF can be regarded as the overlaps of two pseudocomponents' DTG curves. The decomposition reactions of the pseudocomponents might take place in parallel or in series [39]. The use of the term pseudocomponents indicates that they do not correspond to pure components, they are more like mixtures characterized by different thermal degradation behaviors. It follows from what has been mentioned that each pseudocomponent may contribute to the global mass loss during heat treatment in proportional to their weight percentages.

\subsubsection{Kinetic analysis of pseudocomponents}

Figure 4 shows the deconvoluted DTG curves for the first (peak 1) and second (peak 2) mass loss processes, respectively. For both sets of the curves, the peaks shift towards higher temperatures in response to increasing the heating rate. This tendency may be ascribed to the heat transferring limitation. When the sample was heated in the crucible, the heat transference depends on the structure and thermal conductivity of the phase of the matrix, hence there always exists a temperature gradient within it. If the heating rate is sufficiently low, the outer surface and the inner core of the sample may keep basically the same temperature within certain time range, and the temperature profile can be assumed constant along the cross-section of the sample. On the contrary, higher heating rate may leads to a marked difference in temperature inside the sample. Generally, the inner part of the sample is colder than surface and it follows that higher temperature is needed for the sample to decompose, thus the DTG curves of VLF exhibit a continuous shift to the right $[40,41]$.

TG curves depict the relationship between mass loss of certain sample and temperature (or time), while DTG

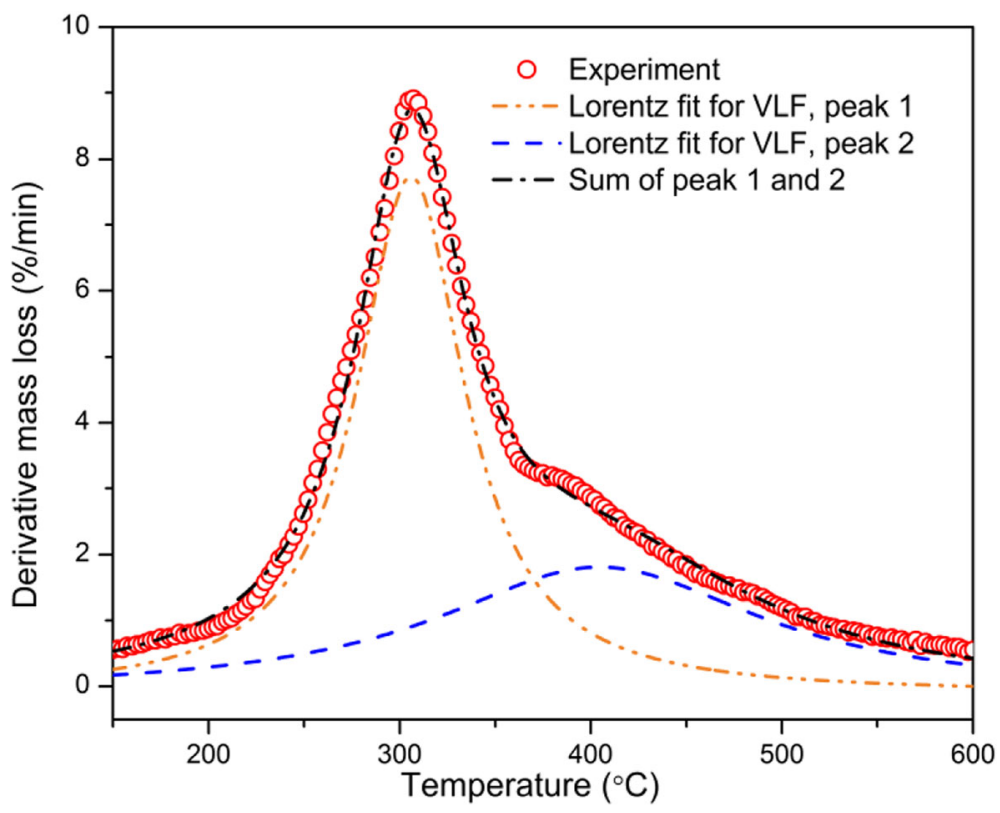

Fig. 3 Deconvolution of the DTG curve at a heating rate of $20^{\circ} \mathrm{C} \mathrm{min}-1$ 


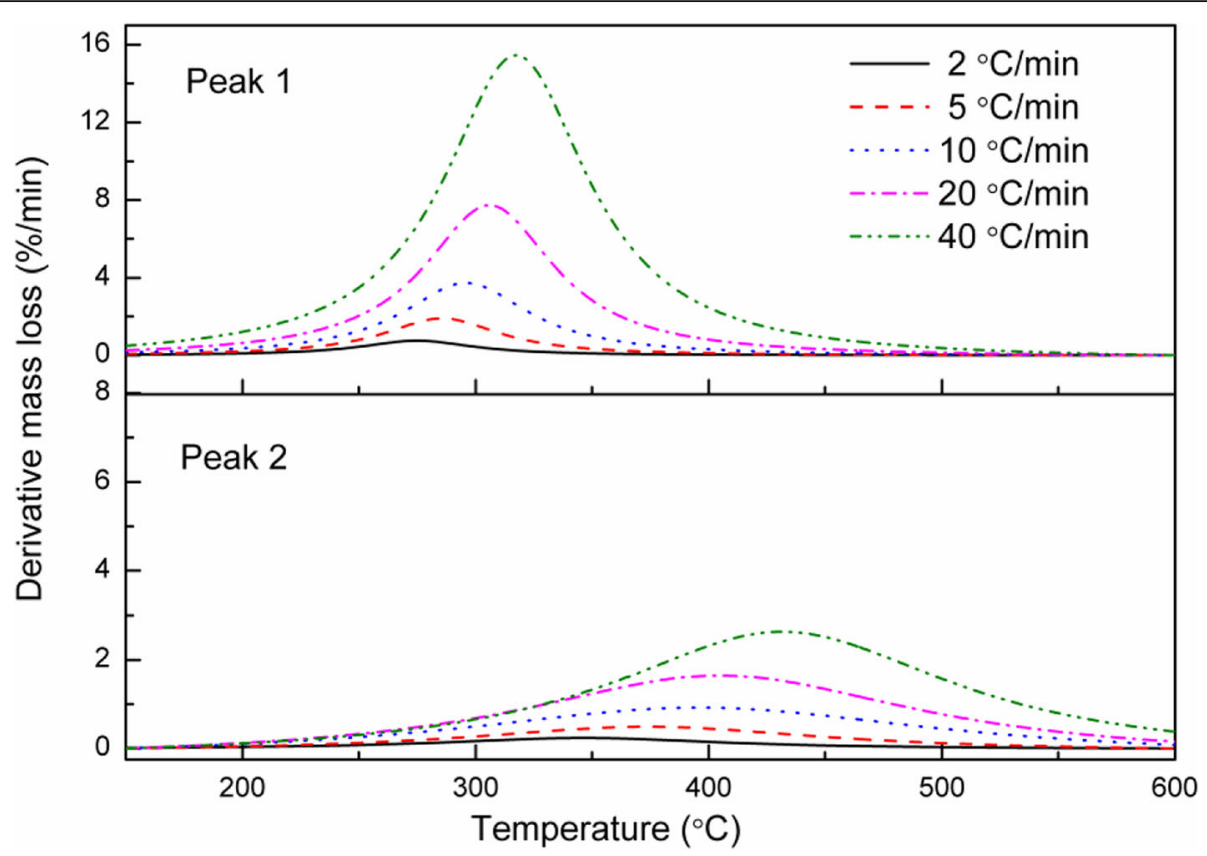

Fig. 4 Sets of peaks obtained by Lorentzian function deconvolution of the DTG corresponding to the first (peak 1, top) and second (peak 2, bottom) degradation process

curves are derivatives of TG curves. Therefore, the mass loss profiles can be reconstructed from any DTG curves by calculating the area under them. Figure 5 shows the integrated TG results of the deconvoluted DTG curves in Fig. 4. Considering the different masses of degraded leather fiber, the areas under the DTG curves were normalized between $0 \%$ and $100 \%$. It is believed that the $E$ values calculated by MKAS method are much more accurate than those obtained by FWO method [22]. Thus MKAS method was employed to the reconstructed TG results to estimate separately the $E$ values of the two thermal degradation processes. From the integrated TG curves in Fig. 5, two sets of regression lines can be obtained according to Eq. (4), as shown in Fig. 6. Then, the

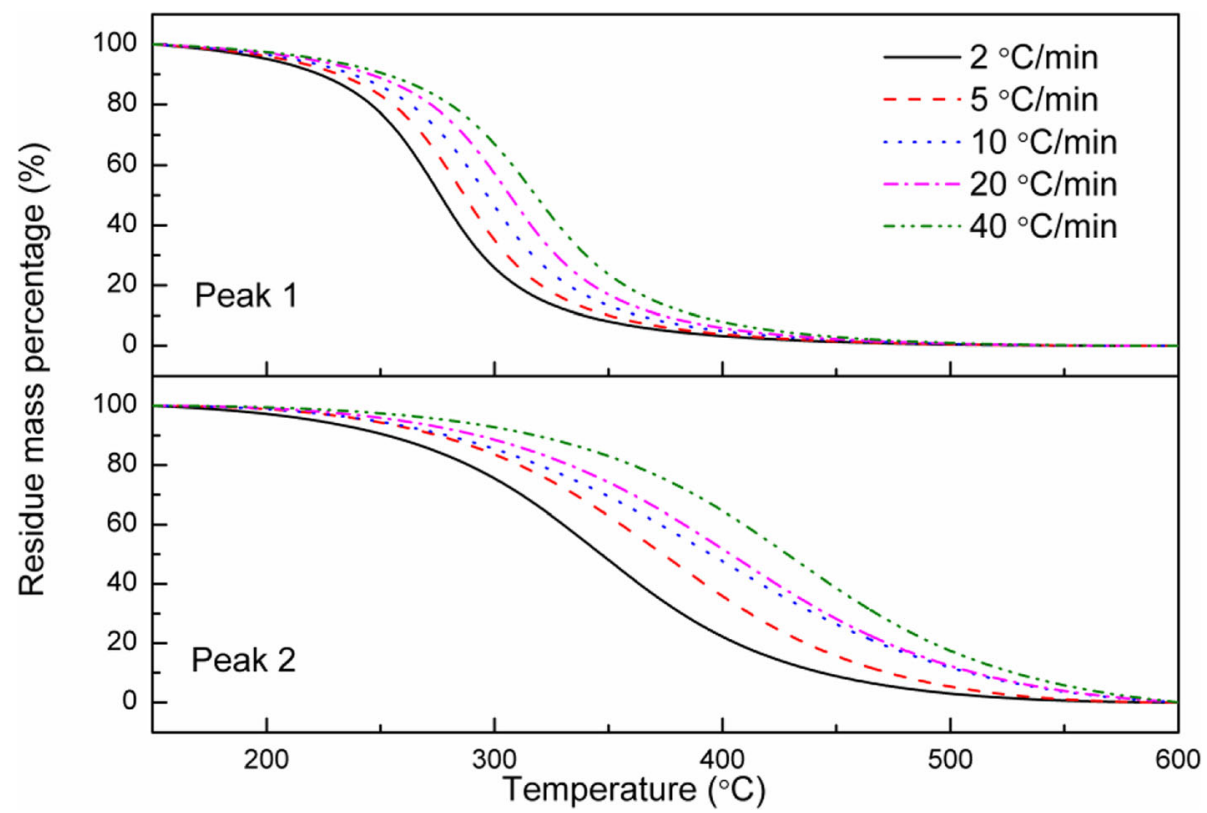

Fig. 5 Sets of reintegrated TG curves corresponding to the first (peak 1, top) and second (peak 2, bottom) degradation process 


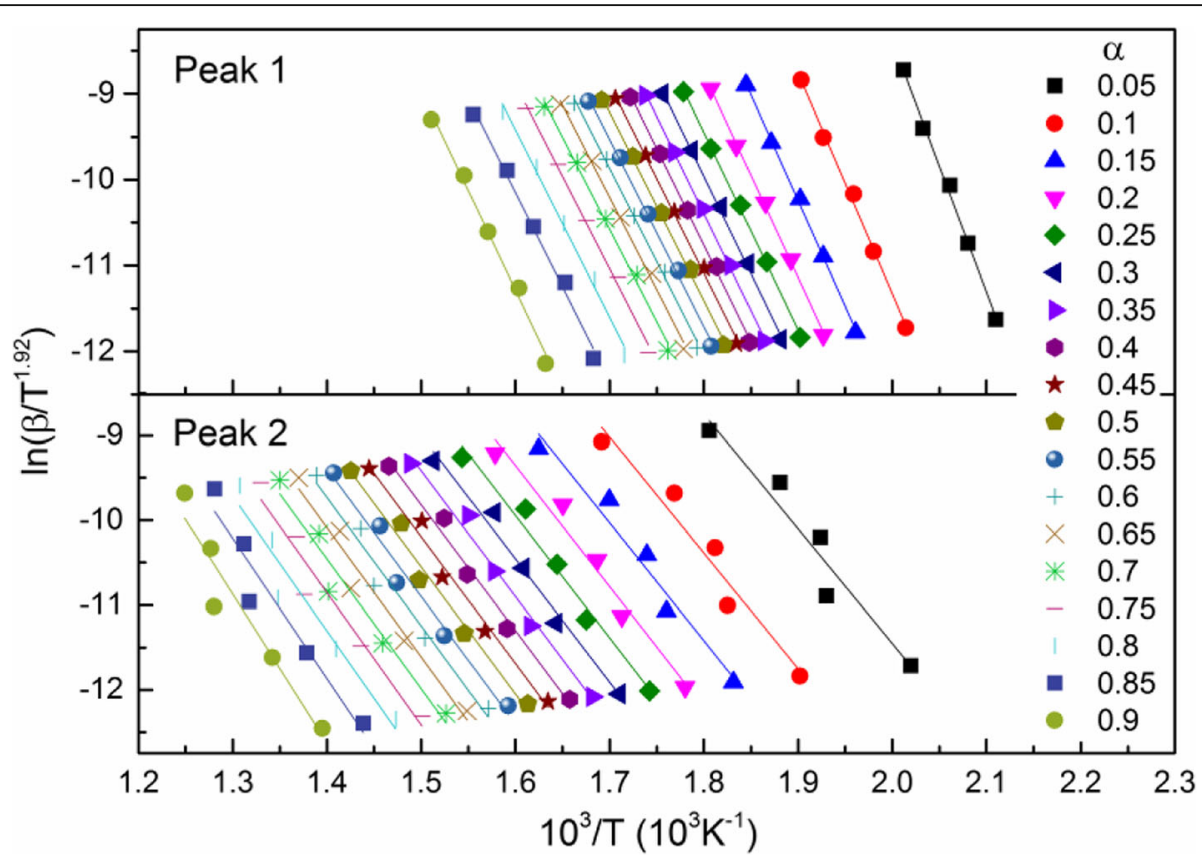

Fig. 6 Isoconversional plots of MKAS method for the first (peak 1, top) and second (peak 2, bottom) degradation process

$E_{\alpha}$ for the peak 1 and peak 2 can be calculated from the slopes of these regression lines. The results of these calculations are given in Fig. 7(a). For comparative purposes, the $E$ values derived from the experimental TG curves are also shown. It should be pointed out that the experimental $E$ values presented here are supposed to be composite or apparent results reflecting the contributions of sub-reaction steps to the overall reaction. Compared to the large variation found in experimental $E$ results, the $E$ values derived from the integrated TG curves are approximately constant over a wide range of conversions for both of the processes. The $E_{0}$ values calculated for the first and second process are 190.6 and $124.8 \mathrm{~kJ} \mathrm{~mol}^{-1}$, respectively. It seems particularly interesting that less reactive pseudocomponent decomposes earlier than more reactive pseudocomponent, since the former always has higher $E_{O}$ value than the latter. In Fig. 7(b), the deviations of $E_{\alpha}$ vs. $E_{0}$ for each pseudocomponent are basically lower than those generated from the experimental TG data. The average deviations for the experimental data, deconvoluted peak 1 and 2 are 13.9\%, $5.7 \%$ and $4.6 \%$, respectively.

It is well known that vegetable tanning is slow and tedious, usually requires various steps and several weeks or even months of time [42]. In such a process, the native collagen fibers are crosslinked to yield a heterogeneous, three-dimensional insoluble network. Consequently, the structural components in the leather samples studied here can be roughly divided into two pseudocomponents: highly-crosslinked collagen $(\mathrm{HCol})$ and low-crosslinked collagen (LCol). It is conceivable that the diffusion of tannin molecules into the collagen matrix is an important prerequisite for uniform tanning process. However, vegetable tannins are natural polyphenolic mixtures containing various components with different molecular masses. For example, the molecular weight of chestnut is between 170 and $1890 \mathrm{Da}$ [43]. As a result, the extent of crosslinking of the outer sheath layer of leather fiber might be higher than that of the inner core, due to the concentration and composition gradients of tannins in the fibers. It can be observed from Additional file 1: Figure S1 that VLF is a bundle of collagen fibrils, whose diameter varies from several micrometers to tens of micrometers, while the collagen fibril's diameter varies from several tens of nanometers to over $100 \mathrm{~nm}$. This makes it possible to form a sheath-core structure after tanning with vegetable tannins. When the leather fiber samples are linearly heated, the highly-crosslinked outer layer of the VLF will be decomposed earlier than the low-crosslinked inner one, also due to the temperature gradient. The heat transferring limitations and decomposition products formed on the surface of the leather fiber might be responsible for the delay of the decomposition of LCol. The difference in the activation energy of the two pseudocomponents can also be explained by the structure heterogeneity, since higher $E$ value is generally because of the decomposition of the less reactive component (here refers to the $\mathrm{HCol}$ ) in leathers. $\mathrm{Xu}$ et al. proposed to divide the thermal decomposition process of wet blue of pig leather into three subreactions, relating to the pyrolysis of triglyceride, multi- and single-complexation collagen. In their opinion, the number of the coordination sites on chromium ions could be used 

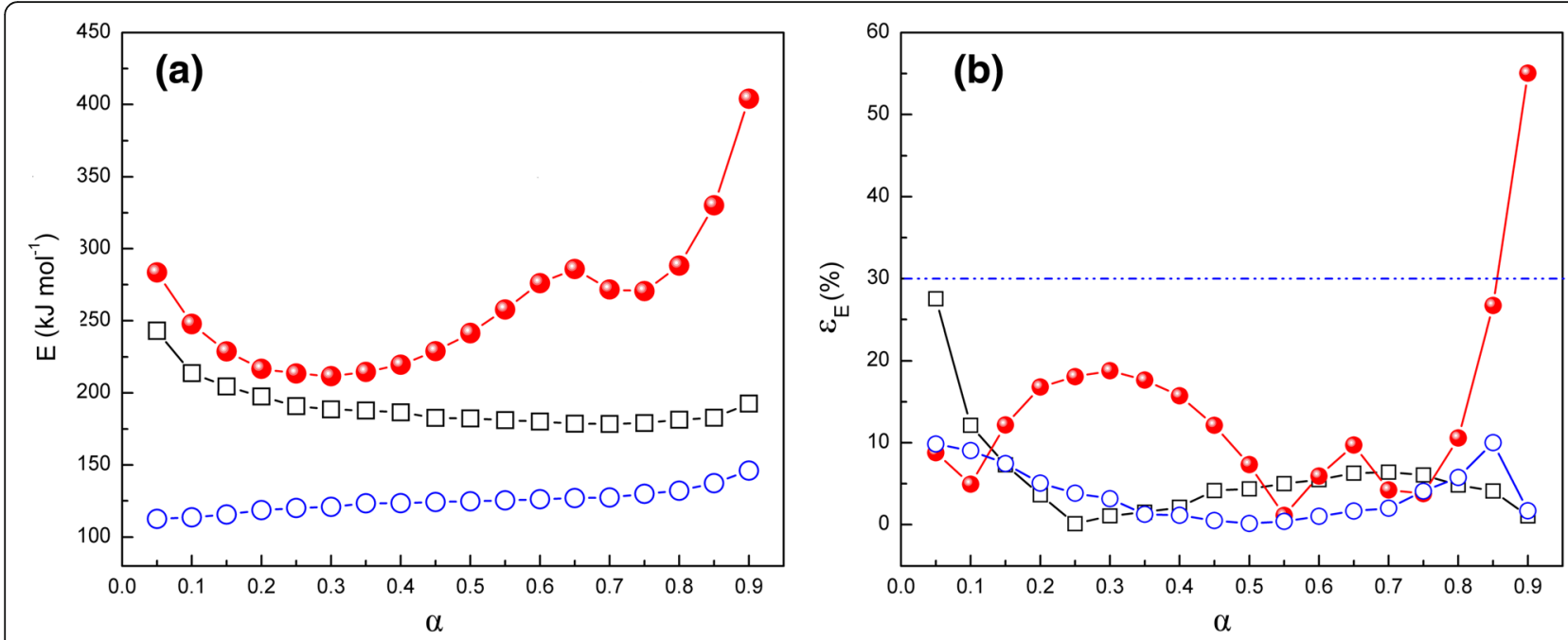

Fig. 7 (a) Activation energy values obtained by MKAS method and (b) absolute deviation vs. a

to distinguish the latter two groups of collagen. In our view, the multi- and single-complexation collagen can be essentially referred to as highly-crosslinked and low-crosslinked collagen fibers, respectively [44].

Comparison of DTG curves for VLF and untanned hide fibers is shown in Fig. 8. An almost symmetrical peak can be clearly observed in the DTG curve of untanned hide fiber, with no shoulder peak in a wide temperature range. The DTG curve of untanned hide fiber can be well simulated by a single Lorentz function. The adjusted $R^{2}$ value for this Lorentz regression model is greater than 0.99 , indicating a good data fitting. The results prove that the composition uniformity is responsible for the difference in DTG curves between VLF and untanned hide fiber. Meanwhile, the comparison of DTG curves reveals that crosslinking has a significant impact on the thermal degradation behavior of leather fiber. In the study of Bañón et al., a shoulder peak in DTG curve was observed too [30]. In the case of Caballero et al., however, no shoulders were found at high temperatures in the DTG curves of tannery waste [18]. It is noteworthy that the dosage of chrome tanning agent used by Caballero et al. was about 5 times higher than that of Bañón et al. This suggested that the crosslinking degree of the leather may be responsible for the difference in DTG curve shapes between

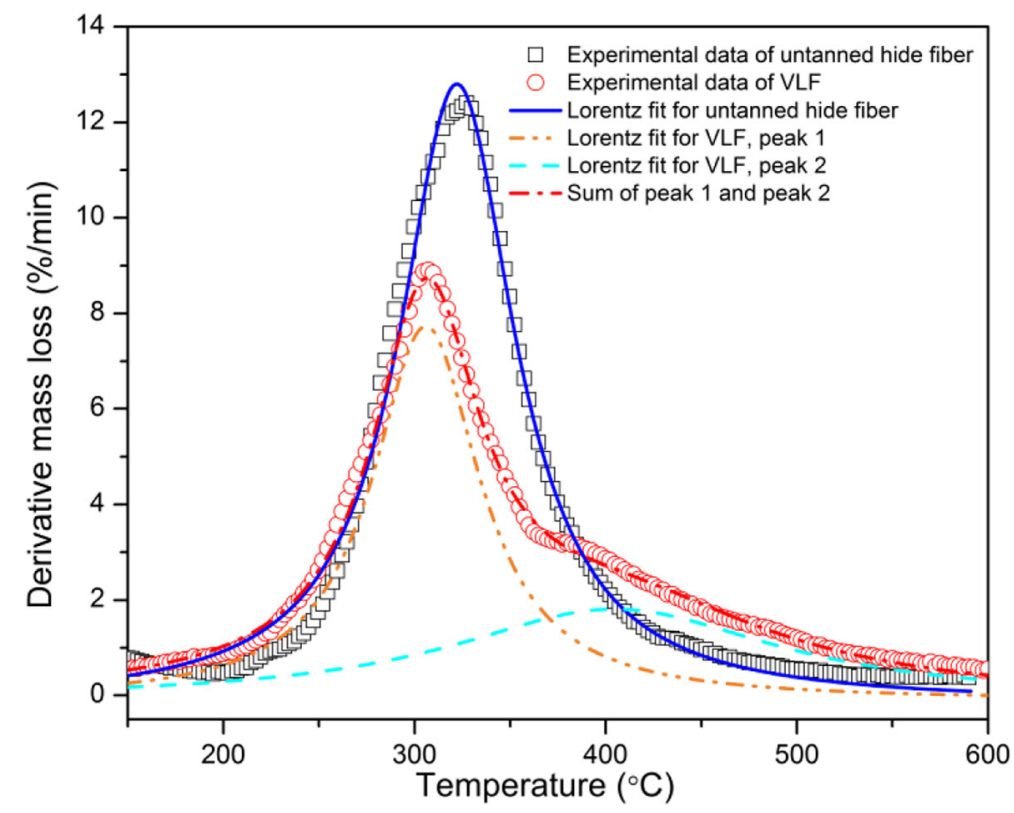

Fig. 8 Deconvolution and Lorentz fitting of DTG curves for VLF and untanned hide fiber at a heating rate of $20^{\circ} \mathrm{C} \mathrm{min}^{-1}$ 
these two works. These studies, together with our results, may support our present hypothesis that the emergence of the shoulder peak in DTG curve is related to the uneven crosslinking structure in leather fibers.

\subsection{Determination of degradation mechanism}

Using the predetermined value of $E_{0}$ obtained from the isoconversional method, along with the experimental values of temperature and $d \alpha / d t$, the item $d \alpha / d \theta$ can be calculated by using Eq. (11). Next, the master plots of $(d \alpha / d \theta) /(d \alpha / d \theta)_{0.5}$ against $\alpha$ from experimental TG data can be obtained. Then, a series of reference theoretical master plots showing the dependence of $f(\alpha) / f(0.5)$ on $\alpha$ should be drawn according to the most commonly used kinetic models (Additional file 1: Table S1). Finally, suitable kinetic model as well as the mechanism for the solid-state degradation process can be determined by comparing the experimental and theoretical master plots. However, unless no clear shoulder peaks are observed in the DTG curve, or the $E_{\alpha}$ value is basically constant over conversion, it is likely that one single-step model can be applied to the entire process. Otherwise, a multi-step kinetic analysis should be performed separately for each reaction step to determine the individual reaction model [22].

Herein, generalized master plots method was applied to analyze the reconstructed TG data of each pseudocomponent. According to the theory, the generalized master plots depend entirely on the kinetic model that the reaction follows. For this reason, the shapes of the experimental generalized master plots should be similar, irrespective of the heating rate [25]. The theoretical and experimental generalized master plots of the degradation of pseudocomponents $\mathrm{HCol}$ and LCol are shown in Fig. 9. The $E_{O}$ values obtained from MKAS method were used in the construction of these master plots. From Fig. 9, it is evident that the experimental master plots obtained at different heating rates are practically similar in shape. This confirms that the degradation kinetics of each pseudocomponent are independent of the heating profile [25].

For pseudocomponent $\mathrm{HCol}$, experimental master plots closely match the theoretical master plot using the Avrami-Erofeev model at the $\alpha$ of less than 0.5, as can be observed in Fig. 9(a). Further analysis of the discrepancies between the experimental and theoretical data shown that A16 is the best kinetic model to describe the thermal degradation of HCol. This implied that the thermal degradation in this conversion range is regulated by nucleation and growth processes. When $\alpha>0.5$, the degradation behavior for $\mathrm{HCol}$ tends to random scission mechanism (L2). This mechanism was introduced in recent years and was found suitable for describing several polymer degradation reactions [26]. It should be pointed out that the reaction equations given in Additional file 1: Table S1 are valid when ideal geometrical and physical conditions are met. However, in real experiments and systems, these conditions are always difficult to satisfy. The change in reaction mechanism with the conversion has also been found for biomass and polymers in literatures by means of various analysis methods $[45,46]$. Figure 9(b) shows the experimental generalized master plots for pseudocomponent LCol. The results clearly illustrated that the shape of these curves more resembles the theoretical generalized master curves corresponding to Avrami-Erofeev eq. (A3 or A4). The deviations in the experimental plots from theoretical curves have been observed frequently [22-26, 46], which are mainly due to the presupposed condition differences between the ideal and real processes. Such a determination
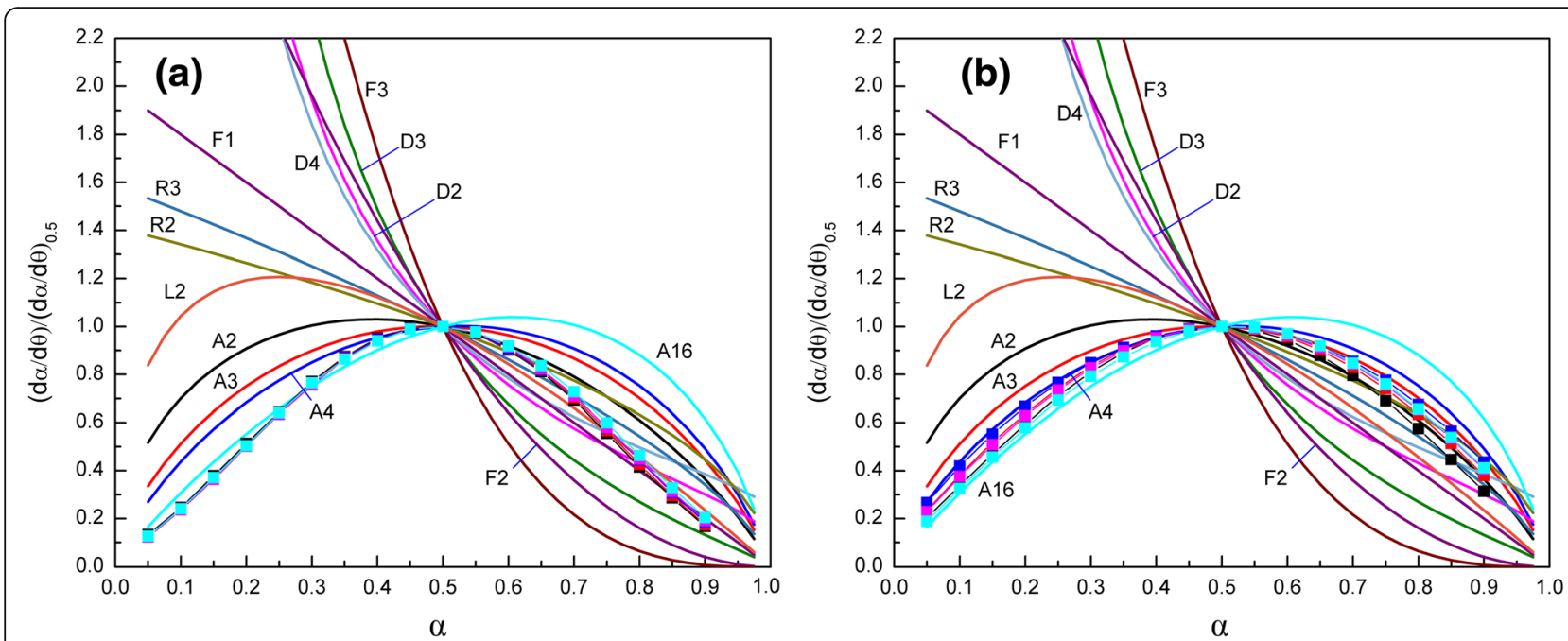

Fig. 9 Theoretical master curves and experimental data obtained using generalized master plots method for (a) HCol and (b) LCol pseudocomponents 
of the kinetic model is very useful and necessary for further detailed degradation analysis and predictions.

\subsection{FTIR analysis of gaseous products from the pyrolysis of VLF}

A typical FTIR spectra of the evolved gases from the pyrolysis of VLF is shown in Fig. 10. It can be seen from the 3D plots (Fig. 10(a)) that a very strong band corresponding to $\mathrm{CO}_{2}$ appears at about $250{ }^{\circ} \mathrm{C}$ and gradually increases up to $900^{\circ} \mathrm{C}$. It has been reported that the initial release of $\mathrm{CO}_{2}$ from collagen is mainly due to the decomposition of free carboxyl groups in glutamic and aspartic acids [47]. With further increase in temperature, $\mathrm{CO}_{2}$ may be generated through condensation reactions relating to protein carbonyl groups. The FTIR spectra of evolved gaseous products at 295 and $395{ }^{\circ} \mathrm{C}$ correspond to peak temperature of deconvoluted peak 1 and 2 were chosen to show the difference and the results are shown in Fig. 10(b). Obviously, the $\mathrm{CO}_{2}$ bands centered at around $2360 \mathrm{~cm}^{-1}$ dominate the spectra of VLF both at 295 and $395^{\circ} \mathrm{C}$. There are also small absorbance peaks observed in the wavenumber ranges of $3500-4000 \mathrm{~cm}^{-1}$ and $1300-2000 \mathrm{~cm}^{-1}$, which are ascribed to the release of moisture from the sample. The characteristic bands of ammonia are observed at $3313 \mathrm{~cm}^{-1}, 964 \mathrm{~cm}^{-1}$ and 926 $\mathrm{cm}^{-1}$. It is considered that ammonia is stem from the cleavage of free $-\mathrm{NH}_{2}$ and peptide - $\mathrm{NH}$ - groups during thermal decomposition [48]. Previous papers reported that pyrrole is a major product formed during pyrolysis of calf-, cattle- and pig-skin $[49,50]$. However, the band of pyrrole couldn't be detected here, likely due to the overlapping of the strong band of $\mathrm{CO}_{2}$ in this region. There exists little difference between the FTIR spectrum of peak 1 and 2. As shown in Fig. 10(b), most of the absorbance peaks at $395{ }^{\circ} \mathrm{C}$ have much enhanced intensity than those at $295^{\circ} \mathrm{C}$, which should be reasonable because more volatiles were produced at higher temperature. Interestingly, it should be noticed that the absorbance peak at $2200 \mathrm{~cm}^{-1}$ (HNCO) was greatly enhanced with the increase in temperature from 295 to $395^{\circ} \mathrm{C}$, which could be due to the pyrolysis of lowcrosslinked collagen domains (fiber core) in VLF.

\section{Conclusions}

The kinetics and mechanism of thermal degradation of vegetable-tanned leather fiber were investigated by thermogravimetric analysis. MKAS, FWO and Friedman methods were used to investigate the dependence of the activation energy value on conversion. The average activation energy of vegetable-tanned leather fiber was found to be $241.9 \mathrm{~kJ} \mathrm{~mol}^{-1}$ by MKAS method. A deconvolution approach was applied to analyze the complex thermal degradation process of VLF. The average activation energy values obtained for the two pseudocomponents representing highly-crosslinked and lowcrosslinked collagen were given as 190.6 and $124.8 \mathrm{~kJ}$ $\mathrm{mol}^{-1}$, respectively. For highly-crosslinked collagen, generalized master plots results indicated that the reaction mechanism could be described by random nucleation and nuclei growth at $\alpha<0.5$. When $\alpha>0.5$, the degradation mechanism tends to L2, which corresponds to random scission. In case of the low-crosslinked collagen, the thermal degradation follows the mechanism of random nucleation and nuclei growth over the entire range of $\alpha$ studied. The gaseous products were also measured and analyzed by TG-FTIR system.
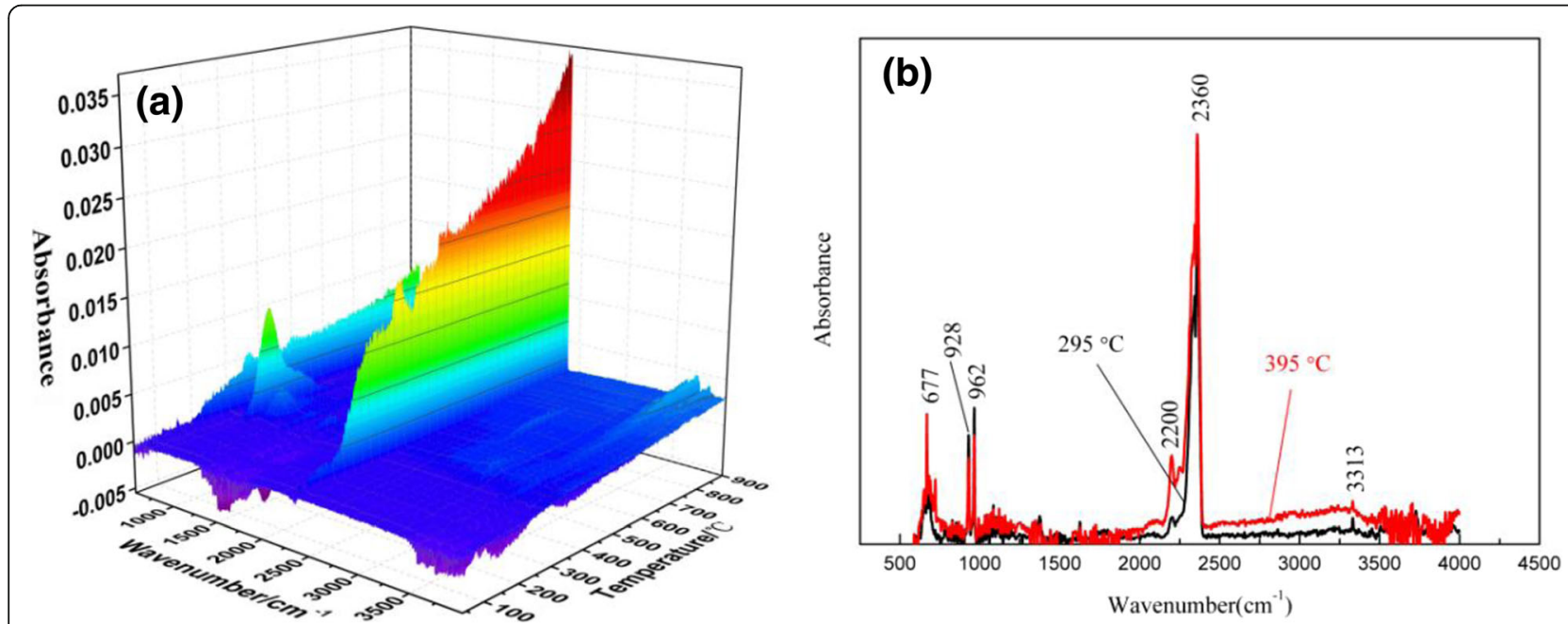

Fig. 10 (a) 3D plots of FTIR spectra of evolved gases in the decomposition of VLF in nitrogen atmosphere, (b) FTIR spectra of evolved gases from VLF at 295 and $395^{\circ} \mathrm{C}$ in nitrogen atmosphere 


\section{Additional file}

Additional file 1: Supporting Information for Kinetics and mechanism of thermal degradation of vegetable-tanned leather fiber. (DOC $2297 \mathrm{~kb}$ )

\section{Acknowledgements}

The authors are grateful to USDA, ARS, ERRC scientists: Cheng-Kung Liu for helpful discussions, Jianwei Zhang for TGA tests, Nickolas P. Latona for sample preparations. The financial supports from the National Key Research and Development Program (2017YFB0308500), the National Natural Science Foundation Commission of China (51673177, U1204504), and Science and Technology Project of Henan Province (172102410022) are greatly appreciated.

\section{Authors' contributions}

All authors read and approved the final manuscript.

\section{Authors' information}

Not applicable.

\section{Funding}

National Key Research and Development Program (2017YFB0308500),

National Natural Science Foundation Commission of China (51673177,

U1204504), Science and Technology Project of Henan Province

(172102410022).

\section{Availability of data and materials}

Not applicable.

\section{Competing interests}

The authors declare that they have no competing interests.

Received: 22 January 2019 Accepted: 9 August 2019

Published online: 02 September 2019

\section{References}

1. Kolomaznik K, Adamek M, Andel I, Uhlirova M. Leather waste-potential threat to human health, and a new technology of its treatment. J Hazard Mater. 2008:160:514-20.

2. Cabeza LF, Taylor MM, DiMaio GL, Brown EM, Marmer WN, Carrió R, Celma PJ, Cot J. Processing of leather waste: pilot scale studies on chrome shavings. Isolation of potentially valuable protein products and chromium. Waste Manag. 1998:18:211-8.

3. Mwinyihija M. Emerging world leather trends and continental shifts on leather and leather goods production. Asia-Pacific J Bus Adm. 2014;1:1-13.

4. Yang J, Shan Z, Zhang Y, Chen L. Stabilization and cyclic utilization of chrome leather shavings. Environ Sci Pollut Res. 2019;26:4680-9.

5. Aslan A. Determination of heavy metal toxicity of finished leather solid waste. B Environ Contam Tox. 2009:82:633-8.

6. Sundar VJ, Gnanamani A, Muralidharan C, Chandrababu KN, Manda AB. Recovery and utilization of proteinous wastes of leather making: a review. Rev Environ Sci Bio. 2011:10:151-63.

7. Bhaskar N, Sakhare PZ, Suresh PV, Gowda LR, Mahendrakar NS Biostabilization and preparation of protein hydrolysates from delimed leather fleshings. J Sci Ind Res. 2007;66:1054-63.

8. Piccin JS, Feris LA, Cooper M, Gutterres M. Dye adsorption by leather waste: mechanism diffusion, nature studies, and thermodynamic data. J Chem Eng Data. 2013:58:873-82.

9. Ashokkumar M, Thanikaivelan P, Murali R, Chandrasekaran B. Preparation and characterization of composite sheets from collagenous and chromiumcollagen complex wastes using polyvinylpyrrolidone: two problems, one solution. Waste Biomass Valori. 2010;1:347-55.

10. Teklay A, Gebeyehu G, Getachew T, Yaynshet T, Sastry TP. Preparation of value added composite boards using finished leather waste and plant fibers-a waste utilization effort in Ethiopia. Clean Technol Envir. 2017:19:1285-96.

11. Liu J, Liu C-K, Brown EM. Development and characterization of genipin cross-linked gelatin based composites incorporated with vegetable-tanned collagen fiber (VCF). J Am Leather Chem As. 2017;112:410-9.
12. Xia G, Sadanand V, Ashok B, Reddy KO, Zhang J, Rajulu AV. Preparation and properties of cellulose/waste leather buff biocomposites. Int J Polym Anal Ch. 2015;20:693-703.

13. El-Sabbagh SH, Mohamed OA. Recycling of chrome-tanned leather waste in acrylonitrile butadiene rubber. J Appl Polym Sci. 2011;121:979-88.

14. Ramaraj B. Mechanical and thermal properties of ABS and leather waste composites. J Appl Polym Sci. 2006;101:3062-6.

15. Mohamed OA, El-Sayed NH, Abdelhakim AA. Preparation and characterization of polyamide-leather wastes polymer composites. J Appl Polym Sci. 2010;118:446-51.

16. Ambrósio JD, Lucas AA, Otaguro H, Costal LC. Preparation and characterization of poly(vinyl butyral)-leather fiber composites. Polym Compos. 2011;32:776-85.

17. Roduit B, Odlyha M. Prediction of thermal stability of fresh and aged parchment. J Therm Anal Calorim. 2006:85:157-64.

18. Caballero JA, Font R, Esperanza MM. Kinetics of the thermal decomposition of tannery waste. J Anal Appl Pyrol. 1998:47:165-81.

19. Yilmaz O, Kantarli IC, Yuksel M, Saglam M, Yanik J. Conversion of leather wastes to useful products. Resour Conserv Recy. 2007:49:436-48.

20. Konikkaraa N, Kennedya $\sqcup$, Vijaya JJ. Preparation and characterization of hierarchical porous carbons derived from solid leather waste for supercapacitor applications. J Hazard Mater. 2016;318:173-85.

21. Kong J, Yue Q, Wang B, Huang L, Gao B, Wang Y, Li Q. Preparation and characterization of activated carbon from leather waste microwave-induced pyrophosphoric acid activation. J Anal Appl Pyrol. 2013;104:710-3.

22. Vyazovkin S, Burnham AK, Criado JM, Perez-Maqueda LA, Popescu C, Sbirrazzuoli N. ICTAC kinetics committee recommendations for performing kinetic computations on thermal analysis data. Thermochim Acta. 2011;520:1-19.

23. Starink MJ. The determination of activation energy from linear heating rate experiments: a comparison of the accuracy of isoconversion methods. Thermochim Acta. 2003:404:163-76.

24. Criado JM, Pérez-Maqueda LA, Gotor FJ, Málek J, Koga N. A unified theory for the kinetic analysis of solid state reactions under any thermal pathway J Therm Anal Calorim. 2003;72:901-6.

25. Sánchez-Jiménez PE, Pérez-Maqueda LA, Perejón A, Criado JM. Generalized master plots as a straightforward approach for determining the kinetic model: the case of cellulose pyrolysis. Thermochim Acta. 2013;552:54-9.

26. Sánchez-Jiménez PE, Pérez-Maqueda LA, Perejón A, Criado JM. A new model for the kinetic analysis of thermal degradation of polymers driven by random scission. Polym Degrad Stabil. 2010;95:733-9.

27. Liu C-K, Latona NP, Taylor MM, Latona RJ. Effects of bating, pickling and cross-linking treatments on the characteristics of fibrous networks from untanned hides. J Am Leather Chem As. 2013;108:79-85.

28. Marcilla A, Leon M, Garcia AN, Bañón E, Martinez P. Upgrading of tannery wastes under fast and slow pyrolysis conditions. Ind Eng Chem Res. 2012;51:3246-55.

29. Gil RR, Girón RP, Lozano MS, Ruiz B, Fuente E. Pyrolysis of biocollagenic wastes of vegetable tanning. Optimization and kinetic study. J Anal Appl Pyrol. 2012;98:129-36.

30. Bañón E, Marcilla A, García AN, Martínez P, León M. Kinetic model of the thermal pyrolysis of chrome tanned leather treated with $\mathrm{NaOH}$ under different conditions using thermogravimetric analysis. Waste Manag. 2016;48:285-99.

31. Chrissafis K. Kinetics of thermal degradation of polymers: complementary use of isoconversional and model-fitting methods. J Therm Anal Calorim. 2009;95:273-83.

32. Katsikas L, Popovic IG. Improvement to the Flynn-Wall method of determining apparent activation energies of the thermal degradation of polymers. J Phys Chem B. 2003;107:7522-5.

33. Aboyade AO, Hugo TJ, Carrier M, Meyer EL, Stahl R, Knoetze JH, Görgens JF. Non-isothermal kinetic analysis of the devolatilization of corn cobs and sugar cane bagasse in an inert atmosphere. Thermochim Acta. 2011;517:81-9.

34. Shanmugharaj AM, Rhee KY, Ryu SH. Influence of dispersing medium on grafting of aminopropyltriethoxysilane in swelling clay materials. J Colloid Interf Sci. 2006;298:854-9.

35. Roeder J, Oliveira RVB, Becker D, Gonçalves MW, Soldi V, Pires ATN. Compatibility effect on the thermal degradation behaviour of polypropylene blends with polyamide 6, ethylene propylene diene copolymer and polyurethane. Polym Degrad Stabil. 2005;90:481-7.

36. SciDAVis, 1.21. Available at http//scidavis.sourceforgenet/.

37. Badea E, Gatta GD, Usacheva T. Effects of temperature and relative humidity on fibrillar collagen in parchment: a micro differential scanning calorimetry (micro DSC) study. Polym Degrad Stabil. 2012;97:346-53. 
38. Walton RS, Brand DD, Czernuszka JT. Influence of telopeptides, fibrils and crosslinking on physicochemical properties of type I collagen films. J Mater Sci Mater Med. 2010;21:451-61.

39. Varhegyi G. Aims and methods in non-isothermal reaction kinetics. J Anal Appl Pyrol. 2007;79:278-88.

40. Maiti S, Purakayastha S, Ghosh B. Thermal characterization of mustard straw and stalk in nitrogen at different heating rates. Fuel. 2007;86:1513-8.

41. Quan C, Li A, Gao N. Thermogravimetric analysis and kinetic study on large particles of printed circuit board wastes. Waste Manag. 2009;29:2353-60.

42. Brenot $\mathrm{A}$, Chuffart $\mathrm{C}$, Coste-Manière I, Deroche $\mathrm{M}$, Godat E, Lemoine L, Ramchandani M, Sette E, Tornaire C. 6-Water footprint in fashion and luxury industry. In: Muthu SS, editor. Water in Textiles and Fashion. Cambridge: Woodhead Publishing; 2019. p. 95-113.

43. Tang HR, Hancock RA, Covington AD. Studies of vegetable tannins characterization of commercial chestnut tannin extract. J Soc Leather Technol Chem. 1996;80:15-24.

44. Xu W, Li J, Liu F, Jiang Y, Li Z, Li L. Study on the thermal decomposition kinetics and flammability performance of a flame-retardant leather. J Therm Anal Calorim. 2016;128:1107-16.

45. Slopiecka K, Bartocci P, Fantozzi F. Thermogravimetric analysis and kinetic study of poplar wood pyrolysis. Appl Energ. 2012;97:491-7.

46. Poletto M, Pistor V, Zeni M, Zattera AJ. Crystalline properties and decomposition kinetics of cellulose fibers in wood pulp obtained by two pulping processes. Polym Degrad Stabil. 2011;96:679-85.

47. Stevens FS, Jackson DS. Purification and amino acid composition of monomeric and polymeris collagens. Biochem J. 1967:104:534-6.

48. Cucos A, Budrugeac P. Simultaneous TG/DTG-DSC-FTIR characterization of collagen in inert and oxidative atmospheres. J Therm Anal Calorim. 2014; 115:2079-87.

49. Kurata S, Ichikawa K. Identification of small bits of natural leather by pyrolysis gas chromatography mass spectrometry. Bunseki Kagaku. 2008;57:563-9.

50. Yang P, He X, Zhang W, Qiao Y, Wang F, Tang K. Study on thermal degradation of cattlehide collagen fibers by simultaneous TG-MS-FTIR. J Therm Anal Calorim. 2017;127:2005-12.

\section{Publisher's Note}

Springer Nature remains neutral with regard to jurisdictional claims in published maps and institutional affiliations.

\section{Submit your manuscript to a SpringerOpen ${ }^{\circ}$ journal and benefit from:}

- Convenient online submission

- Rigorous peer review

- Open access: articles freely available online

- High visibility within the field

- Retaining the copyright to your article

Submit your next manuscript at $\boldsymbol{\nabla}$ springeropen.com 